\title{
Phytases Improve Myo-Inositol Bioaccessibility in Rye Bread: A Study Using an In Vitro Method of Digestion and a Caco-2 Cell Culture Model
}

\author{
Robert Duliński*, Emilia Katarzyna Cielecka, Małgorzata Pierzchalska and Krzysztof Żyła \\ Department of Food Biotechnology, Faculty of Food Technology, University of Agriculture in Krakow, \\ ul. Balicka 122, PL-30-149 Krakow, Poland \\ Received: June 10, 2014 \\ Accepted: January 12, 2015
}

\begin{abstract}
Summary
Preparations of 6-phytase A (EC 3.1.3.26) and phytase B (acid phosphatase, EC 3.1.3.2) were applied alone and combined in the preparation of dough to estimate their catalytic potential for myo-inositol liberation from rye flour in the breadmaking technology. The experimental bread samples were ground after baking and subjected to determination of myo-inositol bioavailability by an in vitro method that simulated digestion in a human alimentary tract, followed by measurements of myo-inositol transport through enterocyte-like differentiated Caco-2 cells to determine its bioaccessibility. Myo-inositol content was measured by a high-performance anion-exchange chromatography with pulsed amperometric detection (HPAEC-PAD) technique. The concentration of myo-inositol in the dialysates of control bread was $25.3 \mu \mathrm{g} / \mathrm{mL}$, whereas in the dialysates of bread sample baked with 6-phytase A, the concentration increased to $35.4 \mu \mathrm{g} / \mathrm{mL}$, and in the bread baked with phytase B to $64.98 \mu \mathrm{g} / \mathrm{mL}$. Simultaneous application of both enzymes resulted in myo-inositol release of $64.04 \mu \mathrm{g} / \mathrm{mL}$. The highest bioaccessibility of myo-inositol, assessed by the measurement of the passage through the Caco-2 monolayer was determined in the bread baked with the addition of 6-phytase A. Enzymatically modified rye bread, particularly by the addition of 6-phytase A, may be therefore a rich source of a highly bioaccessible myo-inositol.
\end{abstract}

Key words: phytic acid, myo-inositol, enzymatically modified bread, Caco-2 cells

\section{Introduction}

Phytic acid (1,2,3,4,5,6-myo-inositol hexakisphosphate) is difficult to digest in the gastrointestinal tract of monogastric animals and humans, and is therefore considered as an antinutritional factor because it reduces bioavailability of minerals, proteins and starch (1). Enzymatic methods of phytate degradation in foods and feeds have gained considerable interest, regarding their numerous advantages over physical or chemical methods (2). Phytases, phosphohydrolases of myo-inositol hexakisphosphate, hydrolyse phytate to a pool of lower myo-inositol phosphates $(3,4)$. In breadmaking, phosphorolytic activity ori- ginates from wheat or rye flour enzymes as well as from the yeast phytase (5-7). The joint action of these enzymes determines the final profile of inositol phosphates and may also lead to the formation of free myo-inositol (8). There are 3-phytases A (myo-inositol hexakisphosphate 3-phosphohydrolase, EC 3.1.3.8), which start catalytic action at C3 atom of the myo-inositol ring, 6-phytases A (myo-inositol hexaphosphate 6-phosphohydrolase, EC 3.1.3.26), which initiate the hydrolysis at the $C 6$, and phytases B (EC 3.1. 3.2), non-specific acid phosphomonoesterases (3). Generally, phytases A are not able to hydrolyse phosphate residue at the $\mathrm{C} 2$ of the myo-inositol ring. Phytase $\mathrm{B}$, on the other hand, may liberate phosphorus from 
any position and therefore concurrent action of phytase $\mathrm{A}$ and phytase B may lead to almost complete dephosphorylation of phytate, and generation of substantial amounts of myo-inositol (4). Myo-inositol is hexahydroxylic cyclohexane derivative present in all types of living cells, in concentrations varying from $0.03 \mathrm{mM}$ in human plasma to $3 \mathrm{mM}$ in brain tissue, cerebrospinal fluid, foetal serum and human milk (9). The content in human diet oscillates between 0.8 and $1 \mathrm{~g}$ per day, more than half of this compound in the form of inositol phospholipids. Decreased levels of myo-inositol are associated with the risk of cataracts, retinopathy, and neuropathy development (10). Studies on rodents and humans demonstrated that myoinositol was effective in treating diabetes and may be a suitable marker for mass screening of diabetes, insulin resistance and glucose intolerance $(11,12)$. Larner et al. (13) proposed a new model of insulin signalling with inositol glycans as putative second messengers. Kim et al. (14) found this substance to be effective in inducing the response of macrophages to bacterial infections and other inflammatory conditions. Okazaki and Katayama (15) found that myo-inositol prevented accumulation of fat in the liver of rats intoxicated with DDT. This compound also regulates fat metabolism in the myocardium of rats with chemically induced diabetes (16). Myo-inositol is also known to exert positive effects in the treatment of psychiatric disorders (17), and is also involved in several aspects of human reproduction (18). Remarkably, some reports indicate that mixtures of myo-inositol and phytate are more effective in cancer cell elimination than these substances administered separately $(19,20)$. In the literature, there are reports that clearly indicate bioactive properties of this compound, which suggests that supplementation of foods with myo-inositol might be a proper way to modulate sugar and lipid metabolism in humans. The strategy presented here is based on the concept of enzymatic conversion of endogenous phytates of rye flour into myo-inositol by means of commercial microbial phytases added to the dough. Although phytase application in the breadmaking has been studied by a few researchers (5$7,21)$, there is no evidence to suggest that this can be utilized as a method for producing bread with enhanced myo-inositol content.

The objectives of the current study are therefore to assess the impact of the addition of 6-phytase A and phytase $\mathrm{B}$, alone or in combination, to the dough on the bioavailability of myo-inositol from rye bread by an in vitro procedure simulating digestion in human alimentary tract. Also, its bioaccessibility is determined by the measurement of an uptake by the Caco-2 cell monolayer.

\section{Materials and Methods}

\section{Enzymes}

The preparation of 3-phytase A (Natuphos ${ }^{\circledR}$ ) was obtained from BASF, Ludwigshafen, Germany, 6-phytase A (Ronozyme $^{\circledR} \mathrm{NP}$ ) was a product of Novozymes, Baggsværd, Denmark, and phytase B (Finase ${ }^{\circledR}$ AP) of AB Enzymes, Rajamäki, Finland. Pepsin and pancreatin were purchased from Sigma Chemical Co (St. Louis, MO, USA). Acid phosphatase activity was determined at $40^{\circ} \mathrm{C}$ by incubating the enzyme with $5.5 \mathrm{mM}$ solution of sodium $p$-nitrophenylphosphate at $\mathrm{pH}=4.5$ for $15 \mathrm{~min}$. The unit of acid phosphatase activity (APAU) was defined as the amount of enzyme which, under the reaction conditions, liberates $1 \mu \mathrm{mol}$ of $p$-nitrophenol during $1 \mathrm{~min}$. One unit of phytase A activity (PAU) was defined as the amount of enzyme that liberates $1 \mu \mathrm{M}$ of inorganic phosphorous from $2 \mathrm{mM}$ of sodium phytate in $1 \mathrm{~min}$ at $40^{\circ} \mathrm{C}$, $\mathrm{pH}=4.5$.

\section{Breadmaking procedure}

Wholemeal rye bread was baked using the following recipe for dough preparation: $1000 \mathrm{~g}$ of wholemeal rye flour type 2000 from Podlaskie Młyny Wodne (Tokary, Poland), $80 \mathrm{~g}$ of an acidifier from Bionat S.A. (Kraków, Poland), $50 \mathrm{~g}$ of lyophilized baker's yeast from Lesaffre P.S. (Łódz, Poland) and $30 \mathrm{~g}$ of table salt from POCh (Gliwice, Poland) were mixed with $720 \mathrm{~mL}$ of tap water. Experimental dough consisted of the above components, but 670 $\mathrm{mL}$ of tap water and $50 \mathrm{~mL}$ of $0.05 \mathrm{M}$ acetate buffer $(\mathrm{pH}=4.5)$ was used. Appropriate amounts of enzyme preparations were diluted in the acetate buffer to obtain 30 APAU or 5000 PAU per kg of flour. The dough ingredients were mixed for 9 min and then dough pieces of $250 \mathrm{~g}$ were formed, put in metal forms and placed in a fermentation chamber at $35^{\circ} \mathrm{C}$ and constant moisture. After 150 min, fermented dough samples were transferred to an oven preheated to $260^{\circ} \mathrm{C}$. After $30 \mathrm{~min}$, the loaves were removed from the oven and left for $2 \mathrm{~h}$ to cool. Baking procedures were performed in triplicates and included a control bread in each run.

\section{In vitro procedure}

Bioavailability of myo-inositol was estimated by an in vitro technique according to the method developed by Zyla et al. (22) and subsequently modified by Starzyńska-Janiszewska et al. (23) to simulate the conditions of human gastrointestinal tract. Half a gram of samples of bread was incubated with $1.7 \mathrm{mg}$ of pepsin (Sigma-Aldrich, Steinheim, Germany; the declared activity was $4750 \mathrm{U} / \mathrm{mg}$ ) dissolved in $0.1 \mathrm{~mol} / \mathrm{L} \mathrm{HCI}$ at $37^{\circ} \mathrm{C}, \mathrm{pH}=2.0$, for $2 \mathrm{~h}$. Next, $2.5 \mathrm{mg}$ of pancreatin (Sigma-Aldrich, from porcine pancreas, $8 \times$ United States Pharmacopeia) dissolved in $0.1 \mathrm{~mol} / \mathrm{L}$ of $\mathrm{NaHCO}_{3}$ were added and the whole samples were incubated in dialysis tubes (Sigma-Aldrich, cellulose membrane $25 \mathrm{~mm} \times 16 \mathrm{~mm}$ ) at $37^{\circ} \mathrm{C}, \mathrm{pH}=7.0$, for $4 \mathrm{~h}$. These incubations simulated the digestion in the stomach and small intestine, respectively.

\section{Cell culture}

The human colorectal carcinoma cell line, Caco-2, was cultured in Dulbecco's modified Eagle's medium (DMEM) supplemented with $10 \%$ of foetal bovine serum (FBS Gold, PAA Laboratories GmbH, Cölbe, Germany) with antibiotics and antimycotics (PAA Laboratories $\mathrm{GmbH})$. Cultures were passed when they had reached $50 \%$ confluence and $5 \cdot 10^{5}$ of cells were seeded on the porous membranes of cell culture inserts (BD Falcon transparent inserts for a 12-well plate, pore diameter $0.4 \mu \mathrm{m}$, $1.6 \cdot 10^{6}$ pores $/ \mathrm{cm}^{2}$, BD (Becton, Dickinson and Company), Franklin Lakes, NJ, USA). The full differentiation to enterocyte-like cells was achieved after sebsequent two weeks of culture. The quality of epithelial layers was regularly monitored by measuring their transepithelial elec- 
trical resistance (TEER) with epithelial voltohmmeter (EVOM, World Precision Instruments, Sarasota, FL, USA). One day before the experiment, the media were changed to serum-free DMEM (SF-DMEM) supplemented with $0.2 \%$ of bovine serum albumin (BSA) in all wells. Cells were serum-starved for $24 \mathrm{~h}$, then $250 \mu \mathrm{L}$ of bread dialysates were added to the apical chambers along with 250 $\mu \mathrm{L}$ of SF-DMEM. In the in vitro control treatment, blanks were used instead of a bread dialysate in the in vitro procedure. Basolateral chambers were filled with $1 \mathrm{~mL}$ of myo-inositol-free SF-DMEM (Institute of Immunology and Experimental Therapy, Wroclaw, Poland). After 48 h, the media were collected from the basolateral and apical chambers, centrifuged at $1000 \times \mathrm{g}$ for $5 \mathrm{~min}$, and frozen at $-80{ }^{\circ} \mathrm{C}$ for future analysis.

\section{Chromatographic system and detection}

Analysis of myo-inositol phosphates in bread samples

Extraction of inositol phosphates from bread samples was conducted according to Gambuś et al. (24). Profiles of the isomers of myo-inositol phosphates were analyzed on the Ultimate 3000 system (Dionex Corporation, Sunnyvale, CA, USA) using high-performance anion exchange chromatography (HPAEC) with postcolumn derivatization and spectrophotometric detection, as described earlier (25).

\section{Analysis of myo-inositol in dialysates}

Chromatograms were generated using HPLC column $\operatorname{Rezex}^{\mathrm{TM}} \mathrm{RCM} \mathrm{Ca}^{2+}(375 \mathrm{~mm} \times 4 \mathrm{~mm}$ i.d., Phenomenex, Torrance, CA, USA) for comprehensive analysis of monosaccharides and sugar alcohols filled with sulphonated styrene-divinylbenzene beads in cross-linked polymer $(8 \%)$ in cationic form $\left(\mathrm{Ca}^{2+}\right)$. The detection was performed using the pulsed amperometric detector (PAD). Analyses were carried out at $25^{\circ} \mathrm{C}$ with flow rates of $0.6 \mathrm{~mL} / \mathrm{min}$ using deionized water as an eluent after postcolumn modification with sodium hydroxide $(200 \mathrm{mM}$, flow rate of $0.15 \mathrm{~mL} /$ min) (26). The HPLC experiments were done in triplicate.

Analysis of myo-inositol in conditioned cell culture media

Chromatograms were generated using Dionex CarboPac ${ }^{\mathrm{TM}}$ MA1 HPLC column $(250 \mathrm{~mm} \times 4 \mathrm{~mm}$ i.d., Dionex Corporation) and the PAD detection system. Analyses were carried out at $25{ }^{\circ} \mathrm{C}$ with flow rates of $1 \mathrm{~mL} / \mathrm{min}$ using linear gradient of deionized water and $1 \mathrm{M} \mathrm{NaOH}$ as the eluent according to the Dionex AN67 brochure. HPLC experiments were done in triplicates. Two different methods were used in the analysis. The Rezex ${ }^{\mathrm{TM}} \mathrm{RCM}$ column (Phenomenex) allowed for a better separation of stereoisomers, chiro- from myo-inositol in the dialysates from the in vitro method, whereas direct detection of myo-inositol on the CarboPac MA1 column by the HPAEC-PAD procedure was more sensitive in the case of myo-inositol determination in the cellular fluids.

\section{Statistical analysis}

Experimental data were subjected to the one-way analysis of variance (ANOVA) to detect significant differences among the results and expressed as a mean value \pm standard error of mean (SEM). The significance of differences was checked by the Tukey's test using STATISTICA for Windows, v. 10 (StatSoft Inc., Tulsa, OK, USA) statistical software.

\section{Results and Discussion}

Loaves of rye bread baked from dough samples with the addition of either 6-phytase A (5000 PAU per $\mathrm{kg}$ of flour) or phytase B (30 APAU per $\mathrm{kg}$ of flour), or a combination of 6-phytase A with phytase B were analyzed by the in vitro procedure that simulated gastric and intestinal digestion in humans to assess bioavailability of myo-inositol. Significant differences among concentrations of dialysable myo-inositol released from bread samples in the in vitro simulation of multiple digestions were observed (Fig. 1). The generation of myo-inositol in the control bread samples was probably caused by the activity of endogenous phytases from rye and yeast phytases. In samples of control bread baked without enzymes the concentration of dialysable myo-inositol was $25.3 \mu \mathrm{g} / \mathrm{mL}$, in the dialysates of bread baked with 6-phytase A $35.49 \mu \mathrm{g} / \mathrm{mL}$, whereas in bread supplemented with phytase B, myo-inositol concentration was almost 2.56-fold higher $(64.98 \mu \mathrm{g} /$ $\mathrm{mL}$ ). However, simultaneous application of both phytases during breadmaking (6-phytase A at 5000 PAU per $\mathrm{kg}$ of flour and phytase B at 30 APAU per $\mathrm{kg}$ of flour) did not enhance dialysable myo-inositol $(64.04 \mu \mathrm{g} / \mathrm{mL})$ above the level obtained with phytase B used as a sole supplemental enzyme. Phytase B as unspecific acid phosphatase most probably releases phosphates in a random way, proportionally decreasing the level of existing inositol phosphates in rye bread and liberating free myo-inositol. In the presence of phytase A, however, the levels of myo-inositol were not higher and the final products were detected as inositol mono- (IP1) and diphosphates (IP2).

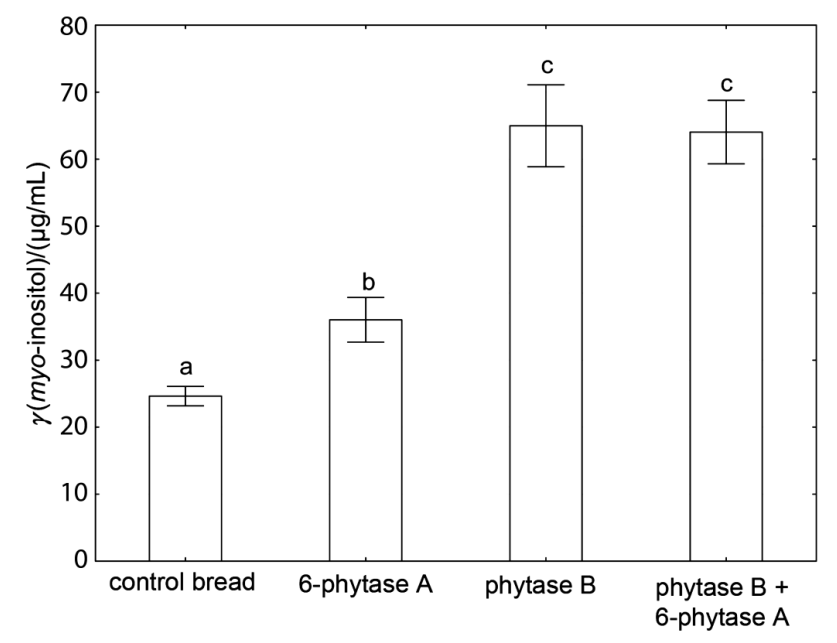

Fig. 1. Concentrations of myo-inositol in the dialysates of enzymatically modified loaves of bread subjected to the in vitro procedure of multiple digestions measured by the HPLC-PAD method. Control bread=rye bread made without enzyme addition, 6-phytase $\mathrm{A}=$ bread supplemented with 6-phytase $\mathrm{A}$ at $5000 \mathrm{PAU} / \mathrm{kg}$ flour, phytase $\mathrm{B}=$ bread made from dough supplemented with phytase B at $30 \mathrm{APAU} / \mathrm{kg}$ flour, phytase B+6-phytase $A=$ rye bread supplemented with both phytases. $P A U=$ phytase A activity units, APAU=phytase B activity units. Different letters denote statistical difference at $\mathrm{p} \leq 0.05$ 
In the next step, bioaccessibility of myo-inositol was assessed by measuring the transport of this compound through the monolayer of the Caco-2 cells. Schematic diagram of the cell culture procedure is depicted in Fig. 2. This cell line derived from colonic adenocarcinoma surprisingly well mimics intestinal cell behaviour upon long culture. The fortnight culture of these cells on porous membranes of inserts leads to the creation of an impervious epithelial layer of polarized cells which resemble mature enterocytes (27). Tissue culture tests provide a relatively quick and cost-effective tool for predicting the absorption of bioactive components by assessing the probability of their transport through epithelial layer (28).

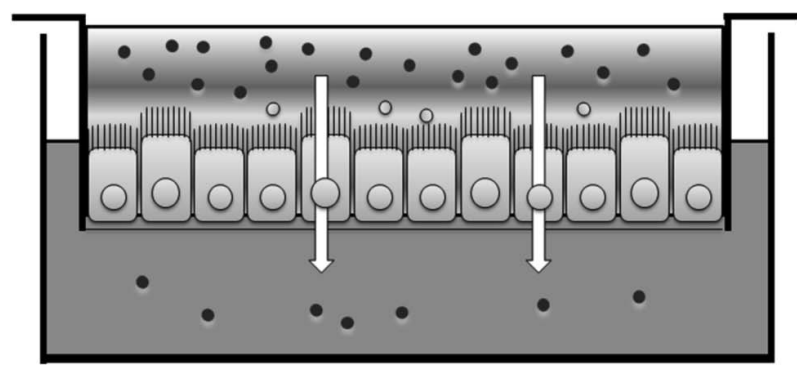

Fig. 2. Schematic diagram of the cell culture. Caco-2 cells were cultured for two weeks on the porous membrane which separates apical and basolateral chambers of the insert to obtain continuous monolayer of differentiated cells. Myo-inositol or dialysates of bread were added from the apical side diluted $(1: 1)$ in $0.5 \mathrm{~mL}$ of myo-inositol-free SF-DMEM medium. A volume of $1 \mathrm{~mL}$ of myo-inositol-free DMEM medium was poured into the basolateral part. After $48 \mathrm{~h}$ the media were collected from both chambers to estimate the paracellular flow of myoinositol. The consistence of monolayers was monitored by measuring the TEER values at the beginning and the end of incubation period. TEER=transepithelial electrical resistance

These tests are often a reasonable alternative to in vivo studies on laboratory animals (e.g. rats) in the analysis of the phytate conversion; however, it should be taken into account that phytase activity in rodent small intestine is 30 -fold higher than in human tissue. In the control experiment three concentrations of myo-inositol were used $(0,25$ and $50 \mu \mathrm{g} / \mathrm{mL}$ ) to demonstrate a relationship between the myo-inositol transport rate and its concentration (Fig. 3). The uptake of myo-inositol by Caco- 2 cell line was found to depend on the myo-insoitol concentration, which is in agreement with the literature data describing two main sodium/myo-inositol cotransporters (29). The fluid from basolateral chambers of inserts from Caco- 2 monolayers exposed for $48 \mathrm{~h}$ to the digest of bread supplemented with phytase $B$ and the fluid from the same chamber before the addition of the digest were analyzed. Caco- 2 cells exposed to the dialysates from digests of bread absorbed myo-inositol from the apical chambers and then secreted it to the basolateral chambers of the inserts.

To our knowledge, this is the first evidence of myo-inositol transport across Caco-2 monolayers. The amounts of myo-inositol secreted to the basolateral chambers from the inserts not exposed (control in vitro) and exposed to the bread digests for $48 \mathrm{~h}$, also expressed as a percentage of the initial amounts of myo-inositol in apical chambers, are given in Table 1 . Total amounts of myo-inositol determined in both the apical and the basolateral chambers at

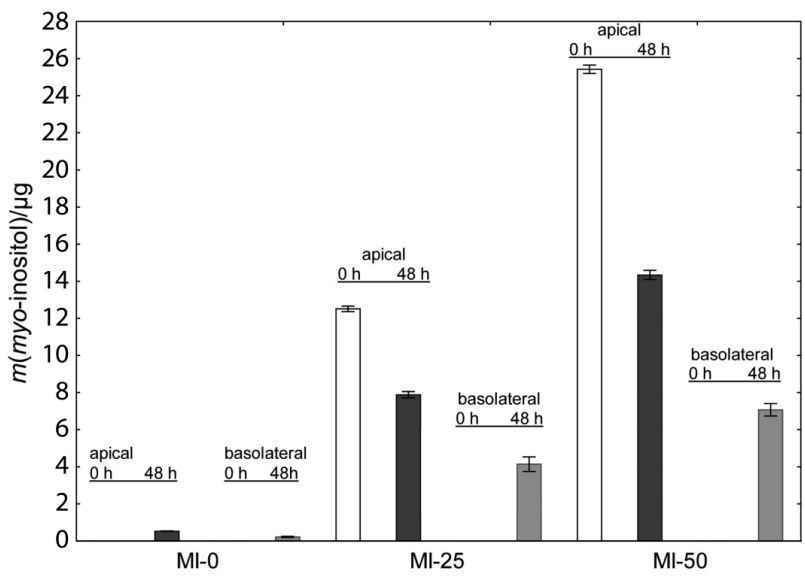

Fig. 3. Control experiment: transport of the myo-inositol through Caco-2 monolayer after $48 \mathrm{~h}$. Total amounts of myo-inositol determined by HPAEC-PAD in both the apical and the basolateral chambers at the beginning of the experiment compared to the total amounts of this compound determined after $48 \mathrm{~h}$ of the Caco- 2 cell culture. MI-0, MI-25 and MI-50=initial concentrations of myo-inositol in the solutions of $0,25,50 \mu \mathrm{g} / \mathrm{mL}$, respectively, were diluted at the ratio of 1:1 with myo-inositol-free SF-DMEM medium

Table 1. Amounts of myo-inositol in the basolateral chambers of the inserts after $48 \mathrm{~h}$ of Caco-2 culture and as a percentage of the initial concentration in the apical chamber

\begin{tabular}{lccc}
\hline Sample & $m(m y o \text {-inositol })_{\mathrm{BC}}$ & & $\frac{\gamma(m y o-\text { inositol })_{\mathrm{BC}}}{\gamma(m y o-\text { inositol })_{\mathrm{AC}}} / \%$ \\
\cline { 2 - 3 } control in vitro & $(5.2 \pm 0.40)^{\mathrm{a}}$ & $(130.5 \pm 14.0)^{\mathrm{c}}$ \\
control bread & $(9.3 \pm 0.4)^{\mathrm{a}}$ & $(149.1 \pm 1.2)^{\mathrm{c}}$ \\
6-phytase A & $(14.7 \pm 0.4)^{\mathrm{c}}$ & $(123.3 \pm 2.8)^{\mathrm{bc}}$ \\
phytase B & $(11.9 \pm 0.3)^{\mathrm{b}}$ & $(61.3 \pm 0.4)^{\mathrm{a}}$ \\
phytase B + & $(12.40 \pm 0.09)^{\mathrm{b}}$ & $(65.9 \pm 1.7)^{\mathrm{a}}$ \\
6-phytase A & & \\
\hline
\end{tabular}

Mean values followed by different letters in superscript are significantly different $(\mathrm{p}<0.05)$

$\mathrm{BC}=$ basolateral chamber, $\mathrm{AC}=$ apical chamber

the beginning of the experiment were subtracted from the total amounts of this compound determined after $48 \mathrm{~h}$ of the Caco- 2 cell culture.

The initial myo-inositol amounts in the apical chambers differed among treatments because a standardized volume of $0.25 \mathrm{~mL}$ of the bread digests or of the reagents used in the in vitro procedure (the control in vitro treatment), mixed with $0.25 \mathrm{~mL}$ of the DMEM solution, was applied on the inserts. Generally, no close relationship was found between myo-inositol amounts in the apical and basolateral chambers of the inserts, which may suggest that specific transport mechanisms rather than passive diffusion phenomena were active in the myo-inositol monolayer metabolism. The highest amounts of myo-inositol were released from the Caco- 2 cells immersed in the digests of bread modified with the addition of 6-phytase A, whereas significantly lower amounts of this compound were determined in the basolateral chambers of inserts filled with the dialysate of bread made with phytase B. The amounts of myo-inositol determined in the basolater- 
al chambers after $48 \mathrm{~h}$ of Caco- 2 culture accounted for 123 $\%$, and for $61 \%$ of its initial amounts in the apical chambers filled with the digests of bread made with the addition of 6-phytase $\mathrm{A}$, and phytase $\mathrm{B}$, respectively.

It seems possible that Caco-2 cells dephosphorylated myo-inositol phosphate intermediates generated by 6-phytase A, but were unable to degrade lower myo-inositol phosphates produced by the catalytic action of phytase B. Such hypothesis should be considered because these enzymes are known to release two distinct pools of myo-inositol phosphates during their action on myo-inositol hexakisphosphates (phytates). The profiles of myo-inositol phosphates analyzed by HPAEC in the enzyme-modified bread shown in Table 2 may serve as a confirmation of the hypothesis mentioned above. In bread supplemented with phytase B the main fraction is inositol phosphate with 3 to 4 phosphorus moieties, but in the bread made with the addition of 6-phytase A, these were inositol diand triphosphates. The application of both phytases resulted in bread samples whose digests influenced Caco-2 metabolism similarly as in the case of bread baked with phytase B alone. The explanation of this phenomenon is similar to the situation observed in determination of myoinositol in bread subjected to in vitro procedure.

Table 2. Profile of myo-inositol phosphates in rye bread supplemented with phytases analysed by HPAEC

\begin{tabular}{lrcccc}
\hline \multirow{2}{*}{ Sample } & \multicolumn{5}{c}{ Inositol phosphate fraction/\% } \\
\cline { 2 - 6 } & IP2 & IP3 & IP4 & IP5 & IP6 \\
\hline 6-phytase A & 35.43 & 30.69 & 3.44 & 4.33 & 24.63 \\
phytase B & 9.44 & 21.99 & 42.97 & 4.83 & 20.77 \\
phytase B + & 27.14 & 33.99 & 26.78 & 2.95 & 9.14 \\
6-phytase A & & & & & \\
control bread & 16.22 & 27.97 & 38.09 & 8.47 & 9.25 \\
\hline
\end{tabular}

IP2=myo-inositol diphosphate, IP3=myo-inositol triphosphate, IP4=myo-inositol tetraphosphate, IP5=myo-inositol pentaphosphate, IP6=myo-inositol hexaphosphate

An additional evidence of a substantial difference in myo-inositol metabolism in Caco-2 cells subjected to digests from the bread supplemented with 6-phytase A and that supplemented with phytase B is provided in Fig. 4, where the net changes in myo-inositol mass in both apical and basolateral chambers of the inserts in the course of 48-hour culture are shown. In the in vitro control, control bread and 6-phytase A treatments, myo-inositol was synthesised by the Caco-2 cells most probably due to the action of cellular phosphatases on lower myo-inositol phosphates, but in the treatments where the digest contained the products of phytase B, myo-inositol consumption or degradation was evidenced. It can be postulated, therefore, that in contrast to 6-phytase A, the action of phytase $\mathrm{B}$ on the dough components of rye bread must have produced compounds which negatively affected myo-inositol bioaccessibility.

While phytase B seems to be the key activity that determines myo-inositol bioavailability from rye bread, 6-phytase A caused the highest enhancement in its bioaccessibility. Suzuki et al. (30) observed that phytate hydrolysates, especially myo-inositol triphosphates, were able

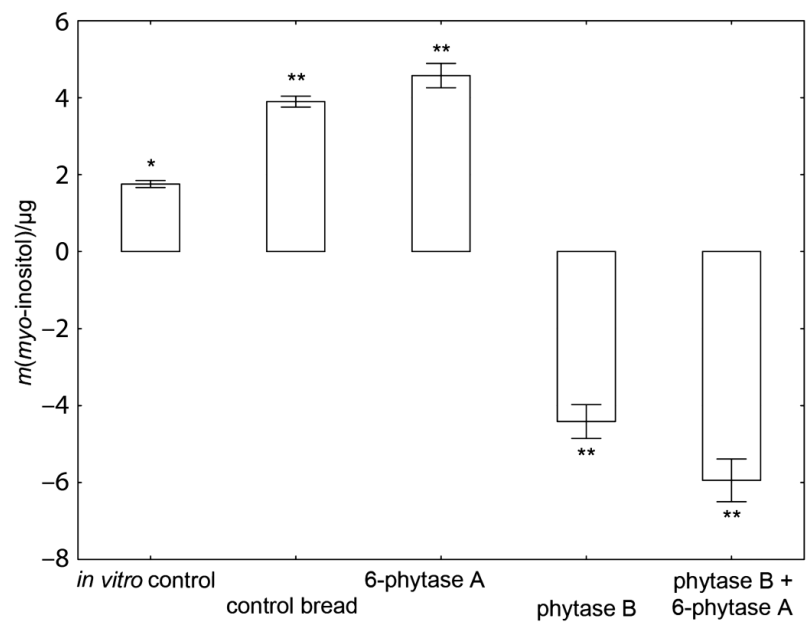

Fig. 4. Myo-inositol balance after $48 \mathrm{~h}$ of culture of the Caco-2 monolayers. Total amounts of myo-inositol determined in both the apical and the basolateral chambers at the beginning of the experiment were subtracted from the total amounts of this compound determined after $48 \mathrm{~h}$ of the Caco- 2 cell culture. In vitro control=culture medium without bread sample addition, control bread=rye bread made without enzyme addition, 6-phytase $\mathrm{A}=$ bread supplemented with 6-phytase A at 5000 PAU per kg of flour, phytase $B=$ bread supplemented with phytase $B$ at 30 APAU per $\mathrm{kg}$ of flour, phytase $\mathrm{B}+6$ phytase $\mathrm{A}=$ rye bread supplemented with both phytases. Significant differences between the final and initial myo-inositol mass at ${ }^{*} \mathrm{p}<0.01$ and ${ }^{* *} \mathrm{p}<0.001$

to induce intracellular signalling in the Caco-2 cell line, and myo-inositol phosphate synthase (MIPS) is known to be regulated by phosphorylation (31). It could not be excluded that physiologically beneficial distribution of myo-inositol triphosphates generated by 6-phytase A stimulated Caco-2 cells to synthesize and effectivelly secrete myo-inositol, thus enhancing its bioaccessibility. Shockravi et al. (21) studied iron and zinc bioaccessibility from breads made from flour with different extraction rates and dephytinized by Aspergillus niger 3-phytase A during in vitro digestion. As a result of phytase application, they reported substantial improvements in bioaccessibility of iron and zinc determined in the Caco-2 cell line.

The current study confirms that myo-inositol is released during hydrolysis of flour phytates in this individual bread-making process more efficiently by phytase $B$ than by 6-phytase A. The 6-phytase A, however, generates myo-inositol which is significantly more bioaccessible. Myo-inositol is known to exert multiple physiological effects that are manifested by antioxidant, immunostimulating and antidepressant properties $(9,32)$. Many important questions regarding dephosphorylation of phytases in cereals have not been addressed yet. This study contributes to the development of an entirely new and innovative approach in breadmaking, involving the enzymatic conversion of phytates, which have antinutritional properties, into myo-inositol - a biostimulating and health-promoting compound.

\section{Conclusions}

The application of proper phytate-degrading enzymes in the technology of rye breadmaking leads to gen- 
eration of myo-inositol - a component with bioactive, health-promoting effects. Its actions include insulin sensitivity modulation, regulation of cholesterol metabolism, central nervous and reproduction system development and maintenance, as well as regulation of the bone calcification processes. Simultaneous application of phytase A and phytase $\mathrm{B}$ or phytase $\mathrm{B}$ alone to the dough leads to the release of 2.4-fold higher amounts of bioavailable myo-inositol, as assessed by an in vitro procedure which simulates digestion in the human intestine. Determination of bioaccessibility of this compound by the measurement of an uptake by Caco-2 cell monolayer revealed that 6-phytase A was the most effective enzyme in enhancing the amount of bioaccessible myo-inositol in the experimental bread. Enzymatically modified rye bread may therefore be a rich source of bioavailable and bioaccessible myo-inositol. Enzymatic generation of myo-inositol seems to be a promissing alternative to a strategy of food supplementation with health-promoting components.

\section{Acknowledgements}

This work was supported by the Ministry of Science and Higher Education of Poland (grant number DS 3700/ WTŻ/2013).

\section{References}

1. Schlemmer U, Frolich W, Prieto RM, Grases F. Phytate in foods and significance for humans: Food sources, intake, processing, bioavailability, protective role and analysis. Mol Nutr Food Res. 2009;53:S330-75. http://dx.doi.org/10.1002/mnfr.200900099

2. Greiner R, Konietzny U. Phytase for food application. Food Technol Biotechnol. 2006;44:125-40.

3. Konietzny U, Greiner R. Molecular and catalytic properties of phytate-degrading enzymes (phytases). Int J Food Sci Technol. 2002; 37:791-812. http://dx.doi.org/10.1046/j.1365-2621.2002.00617

4. Mullaney EJ, Ullah AHJ. Phytases: Attributes, catalytic mechanisms and applications. In: Inositol phosphates: linking agriculture and the enviroment. Turner BL, editor. Wallingford, UK: CABI Publishing; 2006. pp. 97-110.

5. Haros M, Rosell CM, Benedito C. Use of fungal phytase to improve breadmaking performance of whole wheat bread. J Agric Food Chem. 2001;49:5450-4. http://dx.doi.org/10.1021/jf0106421

6. Nielsen MM, Damstrup ML, Thomsen AG, Rasmussen SK, Hansen H. Phytase activity and degradation of phytic acid during rye bread making. Eur Food Res Technol. 2007;225: $173-81$. http://dx.doi.org/10.1007/s00217-006-0397-7

7. Rosell CM, Santos E, Penella JMS, Haros M. Wholemeal wheat bread: A comparison of different breadmaking processes and fungal phytase addition. J Cereal Sci. 2009;50:272-7. http://dx.doi.org/10.1016/j.jcs.2009.06.007

8. Sumengen M, Dincer S, Kaya A, Production and characterization of phytase from Lactobacillus plantarum. Food Biotechnol. 2013;27:105-18. http://dx.doi.org/10.1080/08905436.2013.781507

9. Fisher SK, Novak JE, Agranoff BW, Inositol and higher inositol phosphates in neural tissues: homeostasis, metabolism and functional significance. J Neurochem. 2002;82:736-54. http://dx.doi.org/10.1046/j.1471-4159.2002.01041.x
10. Ola MS, Nawaz MI, Siddiquei M, Al-Amro S, Abu El-Asrar AM. Recent advances in understanding the biochemical and molecular mechanism of diabetic retinopathy. J Diabetes Complicat. 2012;26:56-64. http://dx.doi.org/10.1016/j.jdiacomp.2011.11.004

11. Sarashina G, Yamakoshi M, Noritakea M, Takahashi M, Kurea M, Katsura Y, et al., A study of urinary myo-inositol as a sensitive marker of glucose intolerance. Clin Chim Acta. 2004;344:181-8. http://dx.doi.org/10.1016/s0009-8981(04)00113-5

12. Nascimento NRF, Lessa LMA, Kerntopf MR, Sousa CM, Alves RS, Queiroz MGR, et al. Inositols prevent and reverse endothelial dysfunction in diabetic rat and rabbit vasculature metabolically and by scavenging superoxide. Proc Natl Acad Sci USA. 2006;103:218-23.

http://dx.doi.org/10.1073/pnas.0509779103

13. Larner J, Brautigan DL, Thorner MO, D-Chiro-inositol glycans in insulin signaling and insulin resistance. Mol Med. 2010;16:543-51.

14. Kim WH, Kim JH, An HS, Park KK, Kim BK, Park T. myoInositol restores inflammation-induced downregulation of taurine transport by the murine macrophage cell line RAW 264.7. Life Sci. 2003;73:2477-89.

http://dx.doi.org/10.1016/s0024-3205(03)00656-8

15. Okazaki Y, Katayama T. Effects of dietary carbohydrate and myo-inositol on metabolit changes in rats fed 1,1,1,-trichloro-2,2-bis(p-chlorophenyl)ethane (DDT). J Nutr Biochem. 2003;14:81-9. http://dx.doi.org/10.1016/s0955-2863(02)00279-6

16. Khatiwada J, Verghese M, Walter LT, Shackelford L, Hawan $\mathrm{CB}$, Sunkara R. Combination of green tea, phytic acid, and inositol reduced the incidence of azoxymethane-induced colon tumors in Fisher 344 male rats. Lebensm Wiss Technol. 2006;39:1080-6. http://dx.doi.org/10.1016/j.lwt.2005.07.018

17. Iovieno N, Dalton ED, Fava M, Mischoulon D. Second-tier natural antidepressants: review and critique. J Affect Disord. 2011;130:343-57.

http://dx.doi.org/10.1016/j.jad.2010.06.010

18. Carlomagno G, Nordio M, Chiu TT, Unfer V. Contribution of myo-inositol and melatonin to human reproduction. Eur J Obstet Gynecol Reprod Biol. 2011;159:267-72. http://dx.doi.org/10.1016/j.ejogrb.2011.07.038

19. Vucenik I, Shamsuddin AM. Cancer inhibition by inositol hexaphosphate (IP6) and inositol: from laboratory to clinic. J Nutr. 2003;133:3778S-84S.

20. Lee SH, Choi H. Dietary administration of inositol and/or inositol-6-phosphate prevents chemically induced rat hepatocarcinogenesis. Asian Pac J Cancer Prev. 2005;6:41-7.

21. Shockravi S, Almgren A, Carlson NG, Sandberg AS. Dephytinization of Sangak and Barbari bread made from different extraction rate flours increases iron and zinc bioaccessibility in Caco-2 cells. Int. J Food Sci Technol. 2012;47:2252-8. http://dx.doi.org/10.1111/j.1365-2621.2012.03095.x

22. Zyla K, Ledoux DR, Veum TL. Complete enzymatic dephosphorylation of corn-soybean meal feed under simulated intestinal conditions of the turkey. J Agric Food Chem. 1995;43: 288-94. http://dx.doi.org/10.1021/jf00050a005

23. Starzyńska-Janiszewska A, Stodolak B, Duliński R, Mickowska B. The influence of inoculum composition on selected bioactive and nutritional parameters of grass pea tempeh obtained by mixed culture fermentation with Rhizopus oligosporus and Aspergillus oryzae strains. Food Sci Technol Int. 2012;18:113-22. http://dx.doi.org/10.1177/1082013211414771

24. Gambuś H, Matusz-Mirlak A, Duliński R, Ziobro R, Golachowski A. The influence of extrusion process on myo-inositol phosphate content and profile in snacks containing rye 
bran. Int J Food Sci Nutr. 2012;63(1):41-4.

http://dx.doi.org/10.3109/09637486.2011.595703

25. Blaabjerg K, Hansen-Moller J, Poulsen HD. High-performance ion chromatography method for separation and quantification of inositol phosphates in diets and digesta. J Chromatography B. 2010;87:347-54.

http://dx.doi.org/10.1016/j.jchromb.2009.11.046

26. Cataldi TRI, Margiotta G, Zambonin CG. Determination of sugars and alditiols in food samples by HPAEC with integrated pulsed amperometric detection using alkaline eluents containing barium or strontium ions. Food Chem. 1998;62: 109-15. http://dx.doi.org/10.1016/s0308-8146(97)00154-4

27. Etcheverry P, Grusak MA, Fleige L. Application of in vitro bioaccessibility and bioavailability methods for calcium, carotenoids, folate, iron, magnesium, polyphenols, zinc, and vitamins $\mathrm{B}_{6}, \mathrm{~B}_{12}, \mathrm{D}$, and E. Front Physiol. 2012;3:1-22. http://dx.doi.org/10.3389/fphys.2012.00317

28. Flur SJ, Lim OB, Decker EA, McClements DJ. In vitro human digestion models for food applications. Food Chem. 2011; 125:1-12.

http://dx.doi.org/10.1016/j.foodchem.2010.08.036
29. Ganapathy V, Thangaraju M, Gopal E, Martin PM, Itagaki S, Miyauchi S, Prasad PD. Sodium-coupled monocarboxylate transporters in normal tissues and in cancer. AAPS J. 2008; 1:193-9. http://dx.doi.org/10.1208/s12248-008-9022-y

30. Suzuki T, Nishioka T, Ishizuka S, Hara H. A novel mechanism underlying phytate-mediated biological action-phytate hydrolysates induce intracellular calcium signaling by a Gaq protein-coupled receptor and phospholipase C-dependent mechanism in colorectal cancer cells. Mol Nutr Food Res. 2010;54:947-55.

http://dx.doi.org/10.1002/mnfr.200900279

31. Deraniech RM, He Q, Caruso JA, Greenberg ML. Phosphorylation regulates myo-inositol-3-phosphate synthase: a novel regulatory mechanism of inositol biosynthesis. J Biol Chem. 2013;288:26822-33. http://dx.doi.org/10.1074/jbc.m113.479121

32. Croze ML, Soulage CO. Potential role and therapeutic interests of myo-inositol in metabolic diseases, Biochimie. 2013; 95:1811-27.

http://dx.doi.org/10.1016/j.biochi.2013.05.011 